\title{
OSPREY Model
}

\author{
Veronica J. Rutledge
}

January 2013

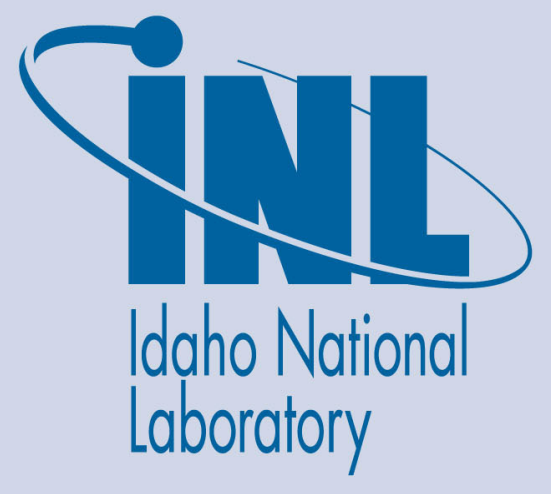

The INL is a U.S. Department of Energy National Laboratory operated by Battelle Energy Alliance 
INL/EXT-13-28150

FCRD-SWF-2013-000086

\title{
OSPREY Model
}

\author{
Veronica J. Rutledge
}

January 2013

\section{Idaho National Laboratory \\ Fuel Cycle Research \& Development Idaho Falls, Idaho 83415}

http://www.inl.gov

Prepared for the

U.S. Department of Energy

Office of Nuclear Energy

Under DOE Idaho Operations Office

Contract DE-AC07-05ID14517 


\section{DISCLAIMER}

This information was prepared as an account of work sponsored by an agency of the U.S. Government. Neither the U.S. Government nor any agency thereof, nor any of their employees, makes any warranty,

expressed or implied, or assumes any legal liability or responsibility for the accuracy, completeness, or usefulness, of any information, apparatus, product, or process disclosed, or represents that its use would not infringe privately owned rights. References herein to any specific commercial product, process, or service by trade name, trade mark, manufacturer, or otherwise, does not necessarily constitute or imply its endorsement, recommendation, or favoring by the U.S. Government or any agency thereof. The views and opinions of authors expressed herein do not necessarily state or reflect those of the U.S. Government or any agency thereof. 


\section{SUMMARY}

The absence of industrial scale nuclear fuel reprocessing in the U.S. has precluded the necessary driver for developing the advanced simulation capability now prevalent in so many other countries. Thus, it is essential to model complex series of unit operations to simulate, understand, and predict inherent transient behavior and feedback loops. A capability of accurately simulating the dynamic behavior of advanced fuel cycle separation processes will provide substantial cost savings and many technical benefits.

The specific fuel cycle separation process discussed in this report is the off-gas treatment system of a used nuclear fuel recycling facility. The off-gas separation consists of a series of scrubbers and adsorption beds to capture constituents of interest. Dynamic models are being developed to simulate each unit operation involved so each unit operation can be used as a stand-alone model and in series with multiple others.

Currently, an adsorption model has been developed within Multi-physics Object Oriented Simulation Environment (MOOSE) developed at the Idaho National Laboratory (INL). Off-gas Separation and REcoverY (OSPREY) models the adsorption of off-gas constituents for dispersed plug flow in a packed bed under non-isothermal and non-isobaric conditions. Inputs to the model include gas composition, sorbent and column properties, equilibrium and kinetic data, and inlet conditions. The simulation outputs component concentrations along the column length as a function of time from which breakthrough data can be obtained. The breakthrough data can be used to determine bed capacity, which in turn can be used to size columns. The model also predicts temperature along the column length as a function of time and pressure drop along the column length.

Experimental data and parameters were input into the adsorption model to develop models specific for krypton adsorption. The same can be done for iodine, xenon, and tritium. The model will be validated with experimental breakthrough curves. Customers will be given access to OSPREY to used and evaluate the model. 


\section{CONTENTS}

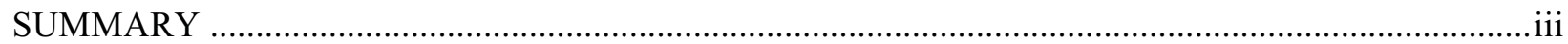

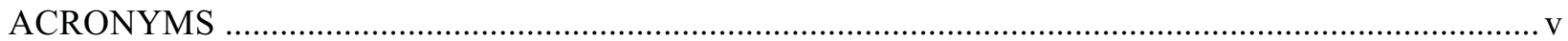

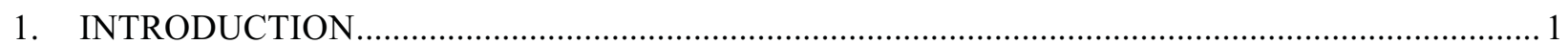

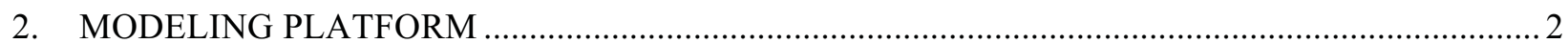

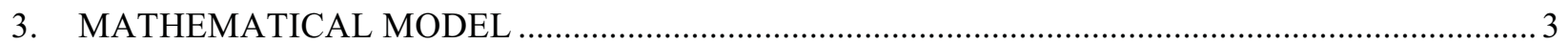

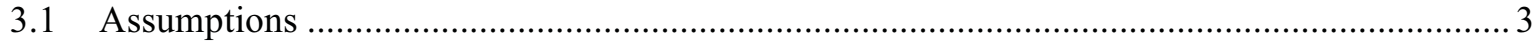

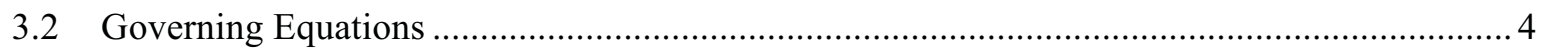

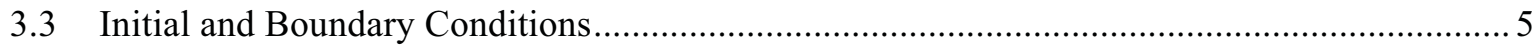

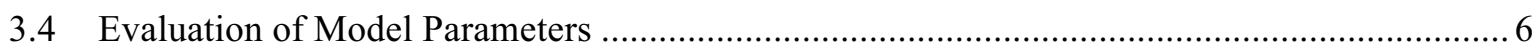



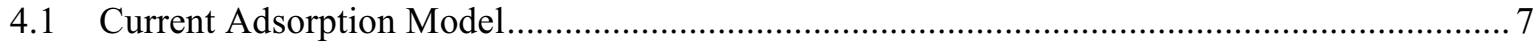

4.2 Future Adsorption Model Work ….................................................................................... 10

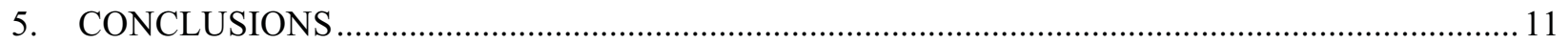

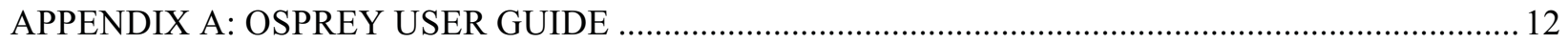



\section{FIGURES}

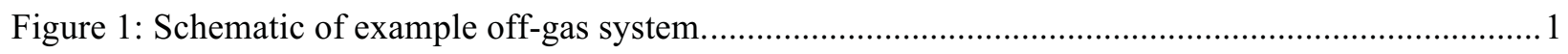

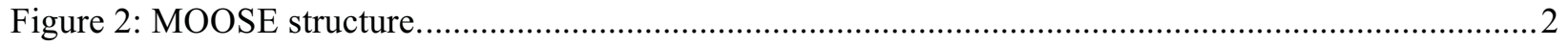

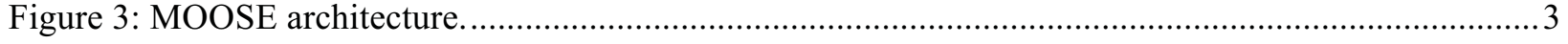

Figure 4: Comparison of concentration results from experimental work, gPROMS prediction and

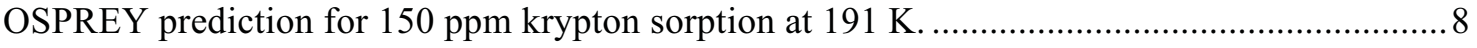

Figure 5: Comparison of experimental and OSPREY breakthrough curves for 150 ppm krypton sorption at $191 \mathrm{~K}$.

Figure 6: Image of what each Peacock tab looks like after running a simulation: 4a. Input file tab 4b. Execute tab 4c. Postprocess tab 4d. Visualize tab. 


\section{ACRONYMS}

DOE Department of Energy

gPROMS general Process Modeling System

LDF Linear driving force

MOOSE Multiphysics Object Oriented Simulation Environment

NE Nuclear Energy

PSE Process Systems Enterprise

OSPREY Off-gas Separation and REcoverY 



\section{SEPARATIONS AND WASTE FORMS OSPREY MODEL}

\section{INTRODUCTION}

Modeling and simulations will aid in the future design of U.S. advanced reprocessing plants for the recovery and recycle of actinides in used nuclear fuel. The design of these processes must not only deliver high purity products but also minimize waste, proliferation risk, environmental impact, process complexity, and cost. The DOE NE Separation and Waste Form Campaign is currently developing a dynamic plant level model that will allow simulations of separation processes for various configurations and operating conditions. This plant model will include the front end of the separations process (dissolution and potential voloxidation of the fuel), the separation processes, and the off-gas treatment system.

An example of the unit operations necessary for separation of off-gas consists of an interconnected series of adsorbers for the capture of tritium, $\mathrm{Kr}, \mathrm{Xe}$, and I, and scrubbers (absorbers) for the capture of $\mathrm{C}-14$ and NOx as shown in Figure 1. Detailed off-gas modeling requirements were developed in FY 2010. These requirements for the off-gas modeling efforts include the model being dynamic, allowing for various unit operations to be incorporated for comparison and being flexible to allow for variation in unit operation sequencing and the components modeled. Also, each unit operation model will be able to be used as a stand-alone model or in series with other unit operation models. ${ }^{1}$ Development of an adsorption model for off-gas treatment systems is the particular area of concern in the work described in this summary.



Figure 1: Schematic of example off-gas system.

The objective of the modeling work presented herein was to solve the fundamental transport equations for adsorption in a packed bed in order to obtain a predictive unit operations model for separation of off-gas constituents. 


\section{MODELING PLATFORM}

The off-gas adsorption model was initially developed using general Process Modeling System (gPROMS) software. The gPROMS approach was described in "Adsorption Model for Off-Gas Separation". The gPROMS platform is an advanced process modeling environment available from Process System Enterprise (PSE). The modeling environment for the off-gas model has been converted from the commercially available gPROMS to INL's MOOSE. This switch was initiated because MOOSE will help expand this model and increase the fidelity of it as modeling efforts continue. MOOSE will allow for more easily coupling unit operations. This conversion will allow for greater future flexibility with predictive modeling including $2 \mathrm{D}$ and $3 \mathrm{D}$ visualization. This also will facilitate collaborative usage of the model amongst national laboratories while avoiding the licensing fee of the gPROMS software.

MOOSE is a framework for solving computational engineering problems in a well planned, managed, and coordinated way. It was designed to significantly reduce the expense and time required to develop new applications. MOOSE uses very robust linear and non-linear solvers, can be easily extended and maintained, and is efficient on both a few and many processors ${ }^{3}$. This framework provides a core set of functionalities and a modular architecture for coupling of multiple physics. It is built upon Libmesh and solver libraries that provide parallel computing utilities. It has an adaptive mesh refinement capability that enables tremendous savings in solving time. Figure 2 shows the structure of MOOSE.

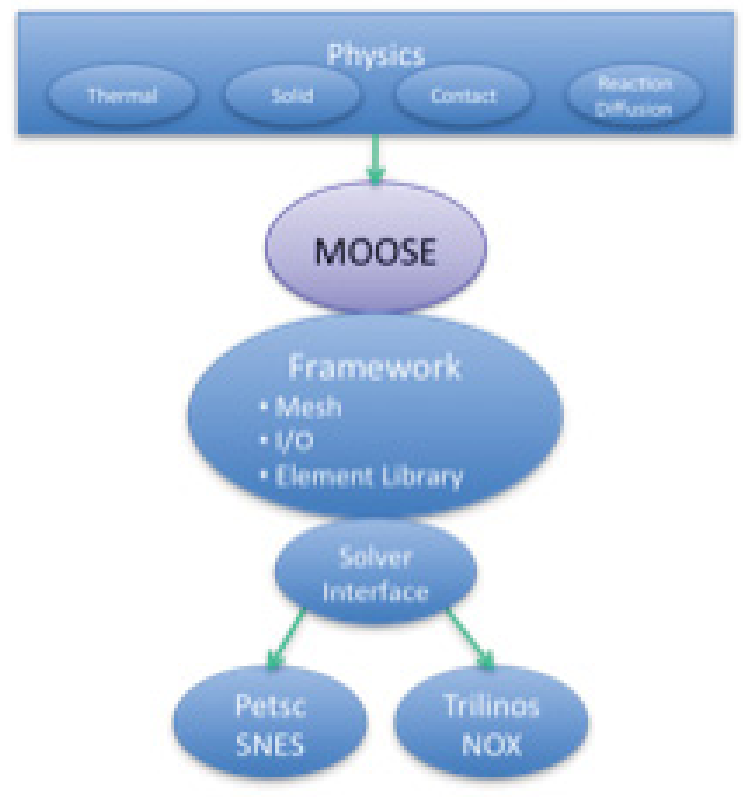

Figure 2: MOOSE structure.

The physics examples in figure 1 can be used as plug-and-play modules. More modules can be generated to go into MOOSE. OSPREY is a MOOSE module that has been developed to describe and couple the physics of gas adsorption. It fully couples the governing equations and uses the interfaces and solvers provided by MOOSE to simulate the adsorption of off-gas. Figure 3 shows the MOOSE architecture. 


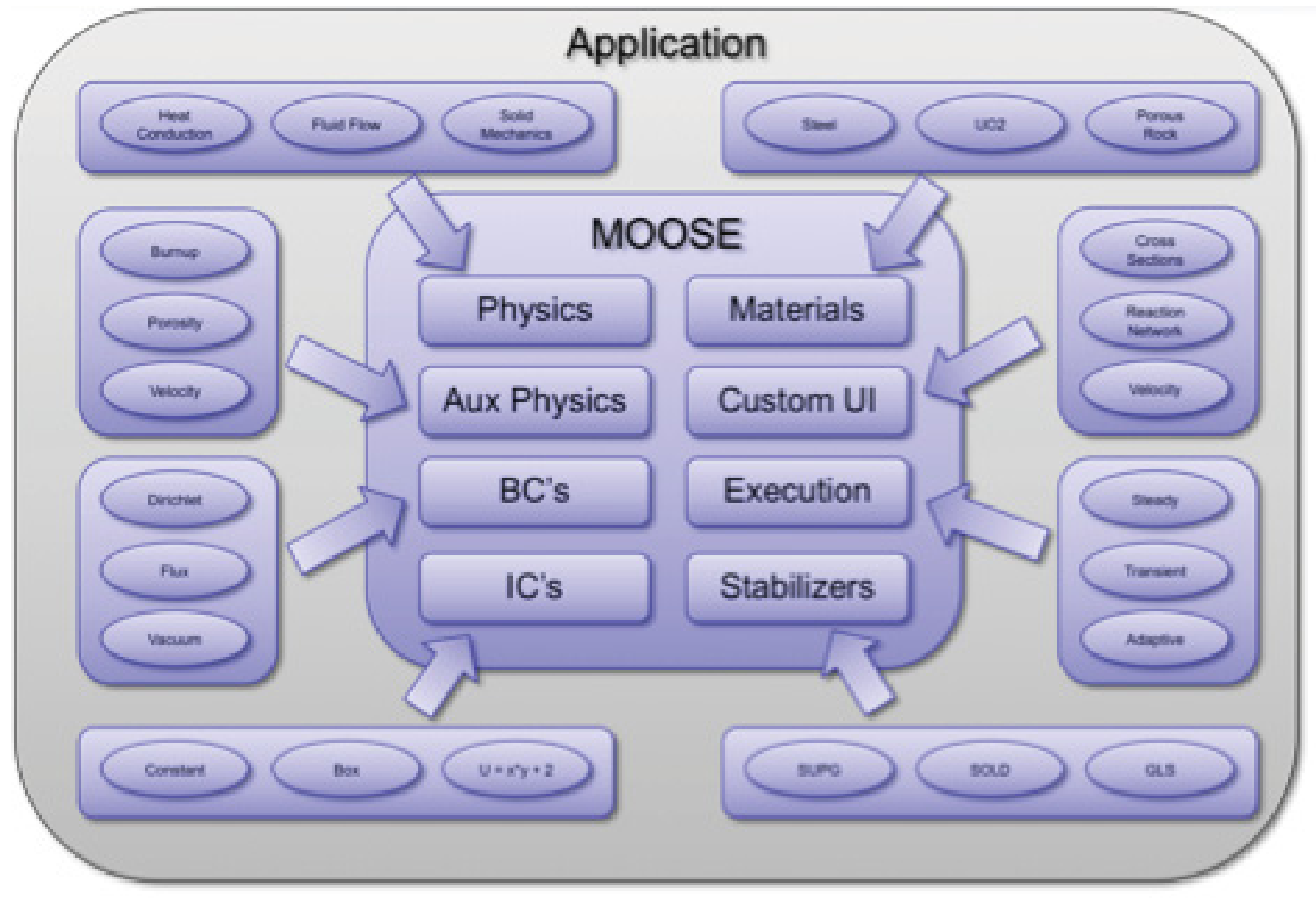

Figure 3: MOOSE architecture.

The architecture in Figure 3 shows how the MOOOSE framework integrates with an application in order to simultaneously solve the governing equations of the application problem. OSPREY is one such application of MOOSE. MOOSE provides templates for developing each of the inputs and fully couples all inputs when solving.

A user-friendly interface has been developed for use for running MOOSE module simulations. This interface is called Peacock and makes it much easier to run OSPREY and view results, especially for users who are not as accustomed with using MOOSE for running simulations. The manual for running OSPREY is provided in Appendix A.

\section{MATHEMATICAL MODEL}

\subsection{Assumptions}

To develop a generalized model for the adsorption bed, the following assumptions for the off-gas separation process were made:

- Axially dispersed plug flow

- Ideal gas behavior

- No radial concentration gradient

- No radial temperature gradient

- Uniform voidage and particle size

- Thermal equilibrium 
- Constant velocity

Due to low concentrations of the adsorbing species, large ratio of length to diameter of the column, and larger bed diameter than particle diameter, the assumptions listed above are reasonable.

\subsection{Governing Equations}

The mass balance describing the concentration gradient of adsorbing species along the adsorption column accounts for the rate of component uptake in the column, the axial dispersion, the convection term, and the rate of mass transfer into the particle. Based on the above assumptions, the mass balance for the adsorbing components is given by:

$$
\frac{\partial C_{i}}{\partial t}=D_{z i} \frac{\partial^{2} C_{i}}{\partial z^{2}}-v \frac{\partial C_{i}}{\partial z}-\frac{\rho_{b}}{\varepsilon} \frac{\partial q_{i}}{\partial t} ; z \in(0, L)
$$

where:

$$
\begin{aligned}
& \mathrm{t}=\text { time, } \mathrm{s} \\
& \mathrm{C}_{\mathrm{i}}=\text { gas phase concentration of component } \mathrm{i}, \mathrm{mol} / \mathrm{m}^{3} \\
& \mathrm{D}_{\mathrm{z}}=\text { axial dispersion coefficient of component } \mathrm{i}, \mathrm{m}^{2} / \mathrm{s} \\
& \mathrm{z}=\text { distance from the bed inlet in the axial direction, } \mathrm{m} \\
& v=\text { superficial gas velocity, } \mathrm{m} / \mathrm{s} \\
& \rho_{\mathrm{b}}=\text { bulk/bed density, } \mathrm{kg} / \mathrm{m}^{3} \\
& \varepsilon=\text { overall bed void, dimensionless } \\
& \mathrm{q}_{\mathrm{i}}=\text { solid phase concentration of component } \mathrm{i}, \mathrm{mol} / \mathrm{kg} \\
& \mathrm{L}=\text { bed length, } \mathrm{m}
\end{aligned}
$$

The rate of mass transfer into the particle, $\mathrm{dq}_{\mathrm{i}} / \mathrm{dt}$, can be described by the linear driving force (LDF) equation:

$$
\frac{\partial q_{i}}{\partial t}=k_{i}\left(q_{i}^{*}-q_{i}\right)
$$

where:

$$
\begin{aligned}
& \mathrm{q}_{\mathrm{i}}^{*}=\text { equilibrium adsorption amount of component } \mathrm{i}, \mathrm{mol} / \mathrm{kg} \\
& \mathrm{k}_{\mathrm{i}}=\text { mass transfer coefficient of component } \mathrm{i}, \mathrm{s}^{-1}
\end{aligned}
$$

The solid phase equilibrium concentrations are represented by the Langmuir equation ${ }^{4}$ :

$$
q_{i}^{*}=\frac{q_{s i} b_{i 0} C_{i}}{1+b_{i 0} C_{i}}
$$

where:

$$
\mathrm{q}_{\mathrm{si}}=\text { maximum concentration in the solid phase for component } \mathrm{i}, \mathrm{mol} / \mathrm{kg}
$$

$\mathrm{b}_{\mathrm{i} 0}=$ Langmuir equilibrium affinity constant for component $\mathrm{i}, \mathrm{m}^{3} / \mathrm{mol}$

The Langmuir parameters $\mathrm{q}_{\mathrm{si}}$, maximum concentration adsorbed, and $\mathrm{b}_{\mathrm{i} 0}$, the Langmuir equilibrium affinity constant, are determined by fitting the single component Langmuir equation to the experimental adsorption isotherm of component $i$.

The pressure distribution along the length of the packed bed is described by the Ergun equation ${ }^{5}$ : 


$$
\frac{\partial P}{\partial z}=-K_{D} v-K_{v} v^{2} ; z \in(0, L]
$$

where:

$$
\begin{aligned}
& \mathrm{P}=\text { pressure }, \mathrm{Pa} \\
& \mathrm{K}_{\mathrm{D}}=\text { viscous pressure loss term } \\
& \mathrm{K}_{v}=\text { kinetic pressure loss terms }
\end{aligned}
$$

For low Reynolds numbers (e.g. $<5$ ), the kinetic contribution to the total pressure loss is negligible, and equation 5 reduces to Darcy's law ${ }^{6}$.

For compressible flow, the energy balance for the packed bed is written as:

$$
\left(C_{p g} \varepsilon \frac{\mathrm{P}}{\mathrm{RT}}+\rho_{b} C_{p s}\right) \frac{\partial T}{\partial t}=K_{z} \frac{\partial^{2} T}{\partial z^{2}}-v \varepsilon \mathrm{C}_{\mathrm{pg}} \frac{P}{R T} \frac{\partial T}{\partial z}-\rho_{b} \sum_{i}\left(H_{a d, i} \frac{\partial q_{i}}{\partial t}\right)+\frac{4 U_{o}}{d_{c}}\left(T-T_{w}\right) ; z \in(0, L)
$$

where:

$$
\begin{aligned}
& \mathrm{C}_{\mathrm{pg}}=\text { gas phase heat capacity, } \mathrm{J} /\left(\mathrm{mol}^{*} \mathrm{~K}\right) \\
& \mathrm{H}_{\mathrm{ad}, \mathrm{i}}=\text { heat of adsorption of component } \mathrm{i}, \mathrm{J} / \mathrm{mol} \\
& \mathrm{C}_{\mathrm{ps}}=\text { solid phase heat capacity, } \mathrm{J} /\left(\mathrm{kg}^{*} \mathrm{~K}\right) \\
& \mathrm{R}=\text { ideal gas constant, } \mathrm{J} /\left(\mathrm{mol} \mathrm{l}^{*} \mathrm{~K}\right) \\
& \mathrm{T}=\text { temperature, } \mathrm{K} \\
& \mathrm{K}_{\mathrm{z}}=\text { effective axial thermal conductivity, } \mathrm{W} /(\mathrm{m} * \mathrm{~K}) \\
& \mathrm{U}_{\mathrm{o}}=\text { overall bed-wall heat transfer, } \mathrm{W} /\left(\mathrm{m}^{2 *} \mathrm{~K}\right) \\
& \mathrm{d}_{\mathrm{c}}=\text { column inner diameter, } \mathrm{m} \\
& \mathrm{T}_{\mathrm{w}}=\text { wall temperature, } \mathrm{K}
\end{aligned}
$$

\subsection{Initial and Boundary Conditions}

Initial conditions $(\mathrm{t}=0)$ for the adsorption process described by the governing equations are given by:

$$
\begin{aligned}
& C_{i}=0 \\
& q_{i}=0 \\
& T=T_{o}
\end{aligned}
$$

where:

$$
\mathrm{T}_{\mathrm{o}}=\text { initial bed temperature, reference temperature, } \mathrm{K}
$$

The boundary conditions used to simulate the process are:

1. Inlet conditions $(\mathrm{z}=0)$

$$
\begin{gathered}
C_{i}=C_{i n, i} \\
T=T_{g, i n} \\
P=P_{\text {in }}
\end{gathered}
$$


where:

$\mathrm{C}_{\text {in. } \mathrm{i}}=$ feed concentration of component $\mathrm{i}, \mathrm{mol} / \mathrm{m}^{3}$

$\mathrm{T}_{\mathrm{g}, \mathrm{in}}=$ feed gas stream temperature, $\mathrm{K}$

$\mathrm{P}_{\text {in }}=$ feed gas pressure, bar

2. Outlet conditions $(\mathrm{z}=\mathrm{L})$

$$
\begin{gathered}
\frac{\partial C_{i}}{\partial z}=0 \\
\frac{\partial T}{\partial z}=0
\end{gathered}
$$

The governing equations describing the adsorption process for off-gas separation along with the initial and boundary conditions were solved in the OSPREY module of MOOSE.

\subsection{Evaluation of Model Parameters}

The intraparticle mass transfer coefficient, $k$, in equation 2 is estimated using values for the effective diffusivity derived from experimental data according to the equation:

$$
k_{i}=60 \frac{D_{e f f, i}}{\left(2 r_{p}\right)^{2}}
$$

where:

$$
\begin{aligned}
& D_{\text {eff,i }}=\text { effective diffusivity of component } \mathrm{i}, \mathrm{m}^{2} / \mathrm{s} \\
& r_{p}=\text { sorbent particle radius, } m
\end{aligned}
$$

The axial distribution coefficient, $\mathrm{D}_{\mathrm{zi}}$, was calculated by the following set of semi-empirical correlations $^{7,8,9}$ :

$$
\begin{gathered}
D_{z i}=v d_{p}\left[\frac{20}{\left(S c_{i}\right)\left(R e_{p}\right)}+\frac{1}{2}\right] \\
R e_{p}=\frac{2 r_{p} \rho_{g} v \varepsilon}{\mu_{g}} \\
S c_{i}=\frac{\mu_{g}}{\rho_{g} D_{m i}} \\
D_{m i}=\frac{10^{-5} T^{1.75}\left(1 / M_{i}{ }^{1} / M_{c g}\right)^{1 / 2}}{P\left[\left(\sum V_{m i}\right)^{1 / 3}+\left(\sum V_{m c g}\right)^{1 / 3}\right]^{2}}
\end{gathered}
$$

where:

$$
\begin{aligned}
& \mathrm{Re}_{\mathrm{p}}=\text { Reynolds number, dimensionless } \\
& \mathrm{Sc}_{\mathrm{i}}=\text { Schmidt number of component } \mathrm{i} \text {, dimensionless } \\
& \rho_{\mathrm{g}}=\text { gas density, } \mathrm{kg} / \mathrm{m}^{3} \\
& \mu_{\mathrm{g}}=\text { gas viscosity, } \mathrm{Pa}{ }_{\mathrm{s}} \\
& \mathrm{D}_{\mathrm{mi}}=\text { molecular diffusion of component } \mathrm{i}, \mathrm{m}^{2} / \mathrm{s} \\
& \mathrm{M}_{\mathrm{i}}=\text { molecular weight of component } \mathrm{i}, \mathrm{kg} / \mathrm{mol} \\
& \mathrm{M}_{\mathrm{cg}}=\text { molecular weight of carrier gas, } \mathrm{kg} / \mathrm{mol} \\
& \Sigma \mathrm{V}_{\mathrm{mi}}=\text { molecular diffusion volume of component } \mathrm{i}, \mathrm{m}^{3} / \mathrm{mol} \\
& \Sigma \mathrm{V}_{\mathrm{mcg}}=\text { molecular diffusion volume of carrier gas, } \mathrm{m}^{3} / \mathrm{mol}
\end{aligned}
$$


The molecular diffusion volumes were calculated by adding atomic diffusion volumes experimentally determined by Fuller, et. al. (1969). ${ }^{7}$

The viscous and kinetic pressure loss terms in the equation 5 are calculated by ${ }^{5}$ :

$$
\begin{aligned}
K_{D} & =150 \frac{\mu_{g}\left(1-\varepsilon_{b}\right)^{2}}{\lambda_{s}^{2} d_{p}^{2} \varepsilon_{b}^{3}} \\
K_{v} & =1.75 \frac{\left(1-\varepsilon_{b}\right) \rho_{g}}{\lambda_{s} d_{p} \varepsilon_{b}^{3}}
\end{aligned}
$$

where:
$\lambda_{\mathrm{s}}=$ shape factor of the sorbent particles
$\varepsilon_{\mathrm{b}}=$ bulk or bed void (packing), dimensionless
$\mathrm{d}_{\mathrm{p}}=$ sorbent particle diameter, $\mathrm{m}$

The effective bed conductivity, $\mathrm{K}_{\mathrm{z}}$, can be expressed as:

$$
\begin{gathered}
\frac{K_{Z}}{k_{g}}=\frac{K_{Z}^{0}}{k_{g}}+a(P r)\left(R e_{p}\right) \\
\operatorname{Pr}=\frac{\mu_{g} C_{p g}}{k_{g}}
\end{gathered}
$$

where:

$$
\begin{aligned}
& \mathrm{K}_{\mathrm{z}}{ }^{0}=\text { static effective thermal conductivity, } \mathrm{W} /(\mathrm{m} * \mathrm{~K}) \\
& \mathrm{a}=\text { constant, dimensionless } \\
& \mathrm{k}_{\mathrm{g}}=\text { gas phase thermal conductivity, } \mathrm{W} /(\mathrm{m} * \mathrm{~K}) \\
& \mathrm{Pr}=\text { Prandlt number, dimensionless }
\end{aligned}
$$

The value for the constant a equals 0.5 and the static effective conductivity accounts for the effects of conduction and radiation. At temperatures of less than $753 \mathrm{~K}$, the radiative contribution to heat transport is small and therefore, negligible. The equation for the static effective conductivity, while neglecting radiative heat transfer is ${ }^{6}$ :

$$
\frac{K_{Z}^{0}}{k_{g}}=\varepsilon_{b}+\frac{\beta_{1}\left(1-\varepsilon_{b}\right)}{\phi+\gamma \frac{k_{g}}{k_{s}}}
$$

where:

$\mathrm{k}_{\mathrm{s}}=$ solid phase thermal conductivity, $\mathrm{W} /(\mathrm{m} * \mathrm{~K})$

$\beta_{1}=$ ratio of effective length between particle centers to the particle diameter, dimensionless

$\phi=$ ratio of effective thickness of fluid film adhering to solid to particle diameter, dimensionless

$\gamma=$ ratio of effective length of solid relating to conduction to particle diameter, dimensionless

The wall-bed heat transfer coefficient, $\mathrm{U}_{\mathrm{o}}$, for cylindrical packing is given by ${ }^{6}$ :

$$
\frac{U_{o} d_{c}}{k_{g}}=1.26 R e_{p}^{0.95} e^{-6 d_{p} / d_{c}}
$$

\section{RESULTS AND DISCUSSION}

\subsection{Current Adsorption Model}

The separation of off-gas constituents modeled in OSPREY by the equations previously described is a single component model that describes the component concentration, gas stream composition, temperature, and pressure along the column as a function of time. It is set up to distinguish between inert and adsorbing species involved in the process to obtain the entire gas composition. The model allows for a wide range of user inputs and can be easily scaled up to be used for systems larger than a bench scale 
model. A wide range of parameter dimensions will be accepted, i.e. column height, various adsorbent properties, and a range of temperatures and velocities.

The conversion from gPROMS platform to the MOOSE framework as OSPREY was successfully completed. The outputs of the two modeling environments show decent agreement, as shown in Figure 4.

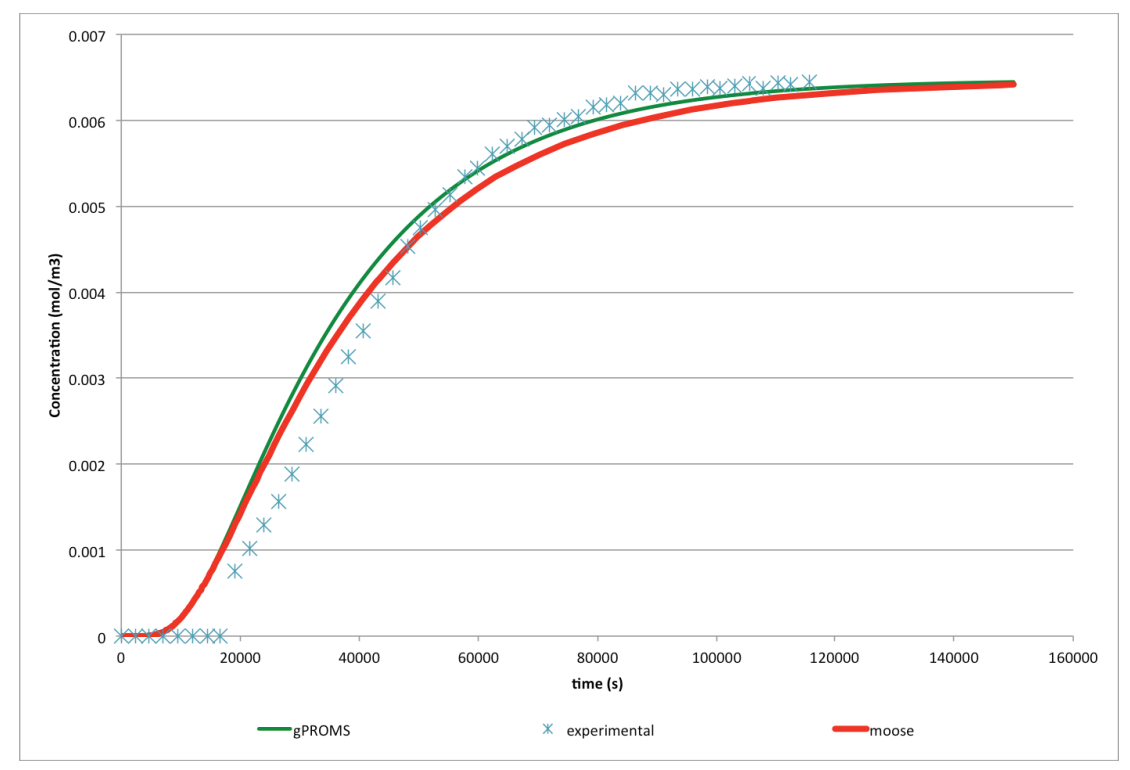

Figure 4: Comparison of concentration results from experimental work, gPROMS prediction and OSPREY prediction for $150 \mathrm{ppm}$ krypton sorption on INL engineered form of $\mathrm{H}$-mordenite at $191 \mathrm{~K}$.

The discrepancies are believed to be due to differences in solving methods. In addition, they both show a good agreement with experimental data. Figure 5 shows the breakthrough curve output by OSPREY compared to experimental data.

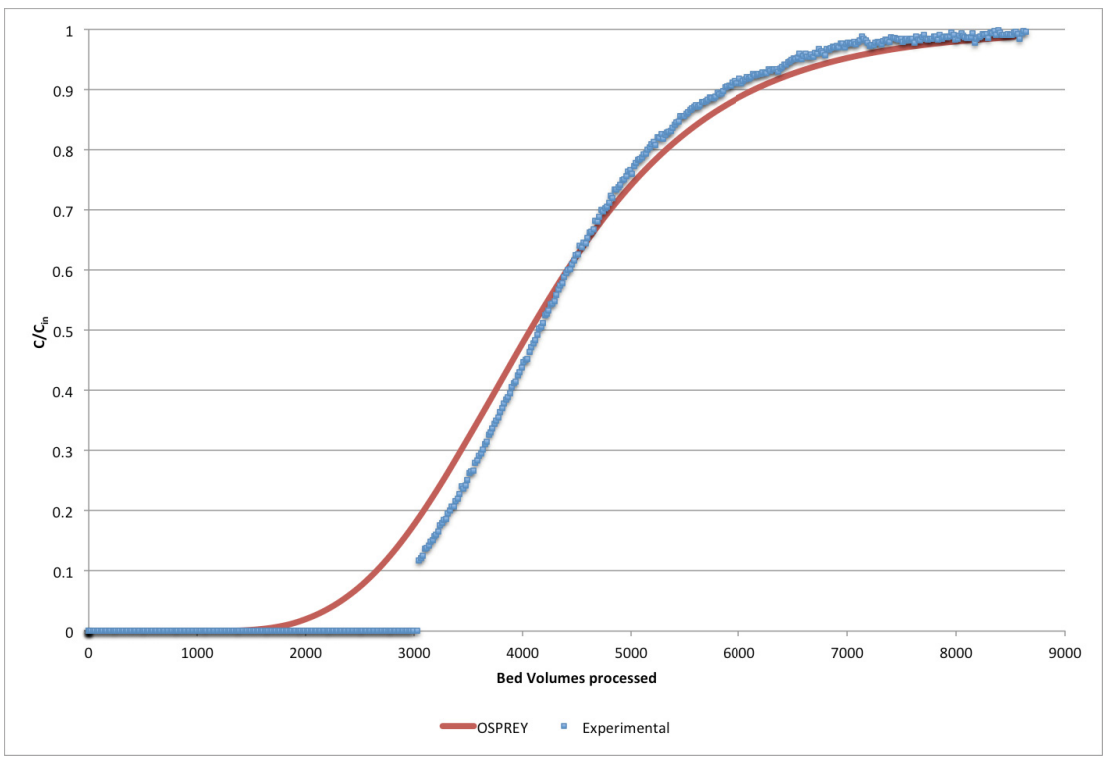

Figure 5: Comparison of experimental and OSPREY breakthrough curves for $150 \mathrm{ppm}$ krypton sorption on INL engineered form of $\mathrm{H}$-mordenite at $191 \mathrm{~K}$.

The discrepancies between the models and experimental data are attributed to the estimation of the parameters. The estimation of the axial distribution coefficient has a large effect on the shifting of the 
curve, which might account for the difference in when breakthrough occurs. However, the predicted curve still gives a good estimate of breakthrough and sorbent capacity. As the parameters are better estimated, more data become available, and further validation is done, this is expected to become a better and tighter fit.

A user-friendly interface, Peacock, has been developed by MOOSE developers and is available for use with OSPREY. This makes it much easier for users of OSPREY to run simulations with their own system specifications. Inputs for the model, which are user specified, include the bed void, sorbent parameters, column specifications, velocity, initial composition, initial temperature, initial pressure, component physical properties, and equilibrium and kinetic parameters. All of these parameters can be specified from within peacock. Figure 5 shows what peacock looks like.

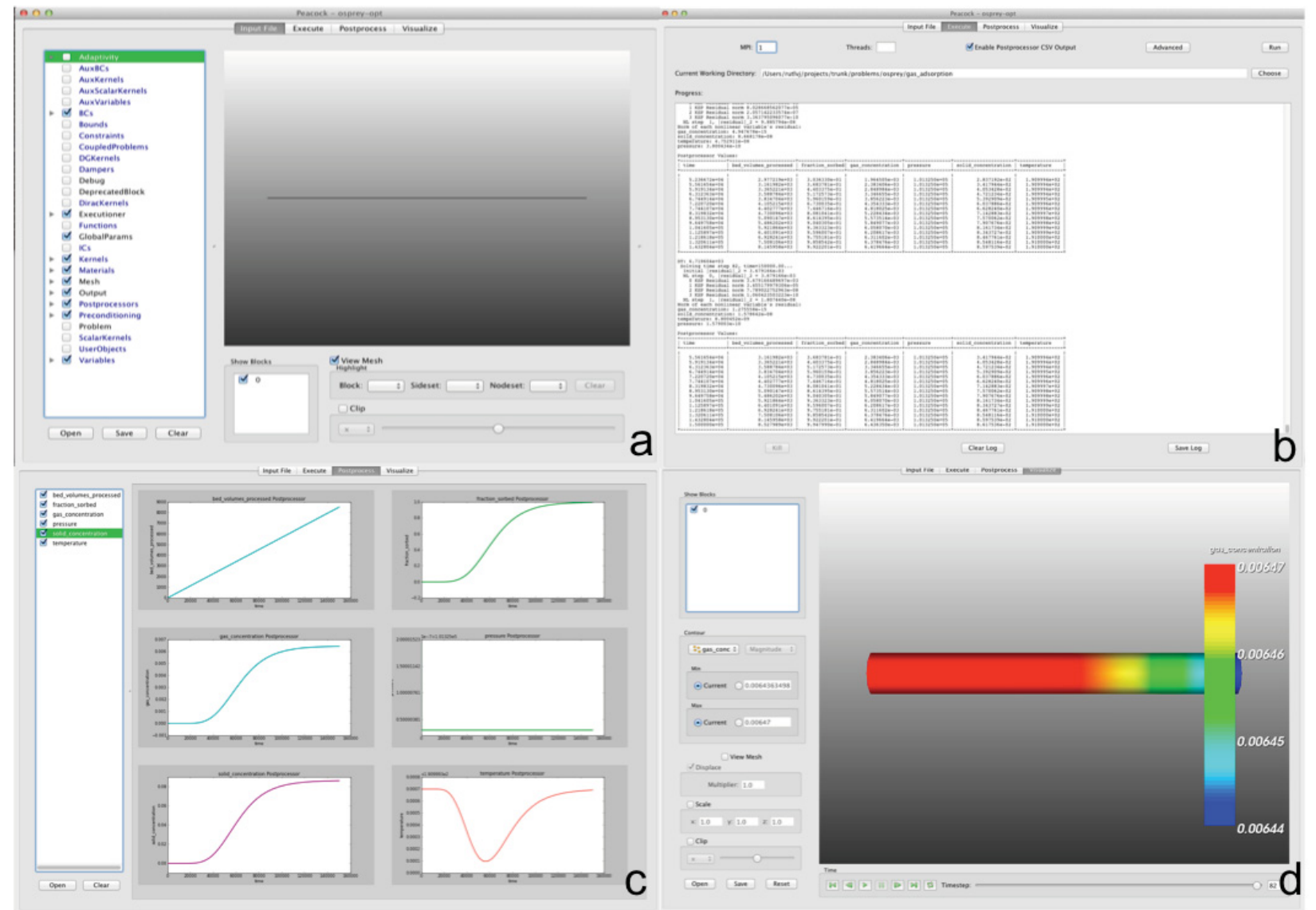

Figure 6: Image of what each Peacock tab looks like after running a simulation: 4a. Input file tab $4 b$. Execute tab $4 c$. Postprocess tab 4d. Visualize tab.

The tabs within Peacock are, as shown in figure 4, input file, execute, postprocess, and visualize. The input file tab (4a) is the tab in which parameters are assigned values. The execute tab is the tab from which the simulation is ran. This tab will show the last 15 data points that were calculated. The postprocess tab (4c) shows plots of the variables as a function of time. The visualize tab (4d) shows the variable gradient along the bed length as a function of time. This can be played and watched while the simulation is running and after the simulation is finished running.

Outputs from the simulation are gas concentration, solid concentration, temperature, pressure, and bed volumes processed at each time step. The results shown in graphical form in the postprocess tab can also be seen in tabular form. These data are also saved as a .csv file that can be opened in excel. A results excel spreadsheet has been developed which will graph these data when copied and pasted from the .csv 
file into the corresponding columns of the results file. It will graph temperature, pressure, and concentration profiles and the breakthrough curve. A user guide for OPSREY is included in Appendix A.

\subsection{Future Adsorption Model Work}

The adsorption model has been developed using parameters determined for krypton adsorption on an INL engineered form of hydrogen mordenite. Experimentally determined parameters are the maximum concentration adsorbed and the equilibrium affinity constant used in equation 3 and the effective diffusivity used to calculate the mass transfer coefficient (equation 14). Additional versions of the model will be developed for other off-gas constituents (i.e. tritium, iodine, and xenon) as experimental data become available. The current version of the model can be used for single component systems (one adsorbing species in a carrier gas) to which the assumptions listed in section 3.1 apply.

Other species specific models that are being considered for generating an application for within OSPREY are krypton and/or xenon adsorption on an INL engineered form of silver mordenite, tritium adsorption on molecular sieve 3A, and iodine adsorption on silver mordenite. For each species specific model developed, both kinetic and equilibrium data are needed. According to literature, tritium adsorption follows a different equilibrium model. To develop the tritium specific model, a literature search will be performed to obtain the needed experimental data from literature. However, iodine, krypton and xenon adsorption data are not as plentiful in literature as tritium data, therefore, experiments will need to be performed to obtain data for these models. The iodine specific model may need to include chemical equilibria because iodine sorption is mainly chemisorption.

As stated in the previous section, the model is currently set up for a single adsorbing component in a carrier gas; however, as seen from the subscripts shown on the equations, the model can be expanded to include multiple components that will adsorb. To do this, the Langmuir equation will need to be modified to the extended Langmuir equation:

$$
\begin{gathered}
q_{i}^{*}=\frac{q_{s i} b_{i}(T) C_{i}}{1+\sum_{i=1}^{n} b_{i}(T) C_{i}} \\
b_{i}(T)=b_{i 0} e^{-H_{a d, i} /(R T)}
\end{gathered}
$$

where:

$$
\begin{aligned}
& \mathrm{b}_{\mathrm{i}}(\mathrm{T})=\text { temperature dependent Langmuir equilibrium parameter of component } \mathrm{i}, \mathrm{m}^{3} / \mathrm{mol} \\
& \mathrm{n} \quad=\text { number of components }
\end{aligned}
$$

In addition, a future plan for the off-gas model is to modify the Langmuir equilibrium parameter to be temperature dependent as shown in equations 25 and 26. The determination of the Langmuir parameters $\mathrm{q}_{\mathrm{si}}$, maximum concentration adsorbed, and $\mathrm{b}_{\mathrm{i} 0}$, the Langmuir equilibrium constant, will be done by fitting the single component Langmuir equation (equation 3 ) to the experimental adsorption isotherm of component $i$. The values of the constants for single component adsorption are regarded to be the same as those used for the extended Langmuir? .

As additional data become available, the model will be further validated and modified. As new versions of the model are completed, they will be saved as a new input file for OSPREY in the MOOSE repository. It will then become available to all OSPREY users when an update is done on their local computer (refer to Appendix A for how to update). 


\section{CONCLUSIONS}

In summary, a dynamic fully coupled off-gas adsorption model (OSPREY) has been developed in the MOOSE framework to solve off-gas separation systems of equations simultaneously in a fully implicit manner using finite elements methods. OSPREY will be used as the framework for the reference case unit operation used for capture of iodine, krypton, and xenon off-gas constituents. This generic model has been created for adsorption in a packed bed column with dispersed plug flow.

The adsorption model is currently being used as a stand-alone model but will also be able to be used in series with other unit operation models. The model will continue to be improved and expanded as more data become available and as feedback is received from evaluation by the Off-gas Sigma Team. 


\section{APPENDIX A: OSPREY USER GUIDE}

NOTICE: This computer software was prepared by Battelle Energy Alliance, LLC, hereinafter the Contractor, under Contract No. DE-AC07-05ID14517 with the United States (U.S.) Department of Energy (DOE). NEITHER THE UNITED STATES GOVERNMENT, NOR DOE, NOR THE CONTRACTOR MAKE ANY WARRANTY, EXPRESSED OR IMPLIED, OR ASSUMES ANY LIABILITY OR RESPONSIBILITY FOR THE USE, ACCURACY, COMPLETENESS, OR USEFULNESS OR ANY INFORMATION, APPARATUS, PRODUCT, OR PROCESS DISCLOSED, OR REPRESENTS THAT ITS USE WOULD NOT INFRINGE PRIVATELY OWNED RIGHTS.

EXPORT RESTRICTIONS. The provider of this computer software and its employees and its agents are subject to U.S. export control laws that prohibit or restrict (i) transactions with certain parties, and (ii) the type and level of technologies and services that may be exported. You agree to comply fully with all laws and regulations of the United States and other countries (Export Laws) to assure that neither this computer software, nor any direct products thereof are (1) exported, directly or indirectly, in violation of Export Laws, or (2) are used for any purpose prohibited by Export Laws, including, without limitation, nuclear, chemical, or biological weapons proliferation.

None of this computer software or underlying information or technology may be downloaded or otherwise exported or re-exported (i) into (or to a national or resident of) Cuba, North Korea, Iran, Sudan, Syria or any other country to which the U.S. has embargoed goods; or (ii) to anyone on the U.S. Treasury Department's List of Specially Designated Nationals or the U.S. Commerce Department's Denied Persons List, Unverified List, Entity List, Nonproliferation Sanctions or General Orders. By downloading or using this computer software, you are agreeing to the foregoing and you are representing and warranting that you are not located in, under the control of, or a national or resident of any such country or on any such list, and that you acknowledge you are responsible to obtain any necessary U.S. government authorization to ensure compliance with U.S. law. 


\section{OSPREY USER GUIDE}

\section{Introduction}

Off-gas Separation and REcoverY (OSPREY) models the adsorption of off-gas constituents for dispersed plug flow in a packed bed under non-isothermal and non-isobaric conditions. Inputs to the model include gas, sorbent, and column properties, equilibrium and kinetic data, and inlet conditions. The simulation outputs component concentrations along the column length as a function of time from which breakthrough data are obtained. The breakthrough data can be used to determine bed capacity, which in turn can be used to size columns. It also outputs temperature along the column length as a function of time and pressure drop along the column length.

\section{Gaining access to OSPREY}

1. To gain access to OSPREY, MOOSE must be set up and the MOOSE repository must be checked out.

a. You will need to apply for an HPC user account if you do not already have one (https://secure.inl.gov/caims/).

b. Contact Derek Gaston (Derek.gaston@inl.gov) to begin this process and be added to MOOSE users.

i. Let him know you will be using, not developing, OSPREY and Peacock and need to get MOOSE setup on your computer. When performing this step also request Peacock and cylindrical visualization in Peacock.

c. MOOSE will not work on Windows; must have either Mac OS X or Linux system. You will need to set up and use port forwarding to interact with the MOOSE SVN repository. The easiest way to setup your Linux or Mac workstation is to use an SSH configuration file to forward ports automatically when connecting to the INL external login node. The following text should be pasted into a file named $\sim /$.ssh/config. (You need to replace $<$ USERNAME $>$ with your username from the INL HPC Enclave in the config file below. You will need to make sure you make all three substitutions. )

\# Multiplex connections for less RSA typing Host *

ControlMaster auto

ControlPath /.ssh/master-\%r@\%h:\%p

\# General Purpose HPC Machines

Host icestorm eos hpcsc flogin1 flogin2 quark

User $<$ USERNAME $>$

ProxyCommand ssh $<$ USERNAME $>@$ hpclogin.inl.gov netcat \%h \%p

\# Forward license servers, webpages, and source control

Host hpclogin hpclogin.inl.gov

User $<$ USERNAME $>$

HostName hpclogin.inl.gov

LocalForward 8080 hpcweb:80

LocalForward 4443 hpcsc:443

d. Once you have an HPC user account set up and have MOOSE access, access the MOOSE wiki (https://localhost:4443/moose).

e. On this page, select your environment under "Getting Started" and then "Download Redistributable Packages". 
i. Follow the instructions on this page.

ii. When checking out the trunk, first create a folder named 'projects' within your home directory and checkout the trunk in this folder.

f. There is a page within the MOOSE wiki that has guidance for offsite MOOSE users (https://localhost:4443.inl.gov/moose/wiki/OffsiteUsers)

2. Once you have OSPREY on your computer, to enable Peacock to be used with OSPREY, you must add peacock to your .bash_profile Path

i. Open bash program (i.e. Terminal)

i1. Open .bash profile file

1. Type: open .bash_profile

2. This file should then open in a text editor

iii. Add a line, after the first line of the .bash_profile file, that looks like the following:

1. export PATH $=\$ H O M E /$ projects/trunk/peacock:\$PATH

2. Add it after the first line of the file

3. Save the file

b. These first 2 should be a one-time step. Each time using OSPREY after initial set up, start at step 3.

\section{Using OSPREY}

3. Open bash profile (i.e. Terminal)

4. Open the trunk directory.

a. The trunk is the folder in which the MOOSE repository checked out in step 1 is located.

b. Line of code to type into bash: cd <address $>$

i. Should be: $c d \sim /$ projects/trunk

5. Update the repository.

a. Type: svn update

b. You may be required to login to your HPC user account. This info should have been provided to you in sometime during process of completing step 1.

6. If it has been a week or more since last using the model, re-configure and rebuild Libmesh just to be sure an important MOOSE or libmesh update was not missed.

a. Type: cd libmesh

i. this opens the libmesh directory

b. Type: ./build_libmesh_moose.sh

i. this configures and builds libmesh

ii. make sure to check for these 3 lines (or 3 very similar to these) while configuring:

$<<<$ Configuring library with MPI from PETSC config $>>>$

$<<<$ Configuring library with PETSc version 3.3.0 support $>>>$

$<<<$ Configuring library with Hypre support $>>>$

1. They will be found optional packages

iii. When libmesh has successfully configured, it should say "Done configuring libmesh". It will then automatically begin building the Libmesh library.

7. Rebuild OSPREY

a. Every day OSPREY is used, it should be updated in case I have modified or added anything to the repository.

b. Type: cd ../osprey

i. This will take you to the osprey directory/folder

c. Type: make cleanall

d. Type: make $-\mathrm{j} 8$ 
i. 8 is the number of processors being used. Adjust this number based on the number of processors you have available.

ii. This will build the OSPREY application

iii. Final line of build should say "Linking/<address>/osprey/osprey-opt"

e. Run Tests to make sure they are working properly

i. Type: ./run_tests

ii. No tests should fail, however, some might get skipped

8. Open input file in peacock

a. Input files are the file I created that brings together all equations and parameters and information needed to run a particular simulation

b. Must go to osprey gas adsorption problems directory

i. Type: cd ../problems/osprey/gas_adsorption

c. List all the files in the directory so you see all available input files (.i files)

i. Type: $1 \mathrm{~s}$

d. Open input file you want to run in Peacock

i. Type: peacock $-\mathrm{i}<$ input_file.i>

1. Example: peacock -i GasAdsorption.i

a. Currently GasAdsorption.i is set up with parameters to simulate krypton sorption

ii. As modifications are made to the model to include other component specific simulations, new input files will be created and show up in this folder for use when an update is performed.

iii. This command will open a window that is shown in figure 1 .

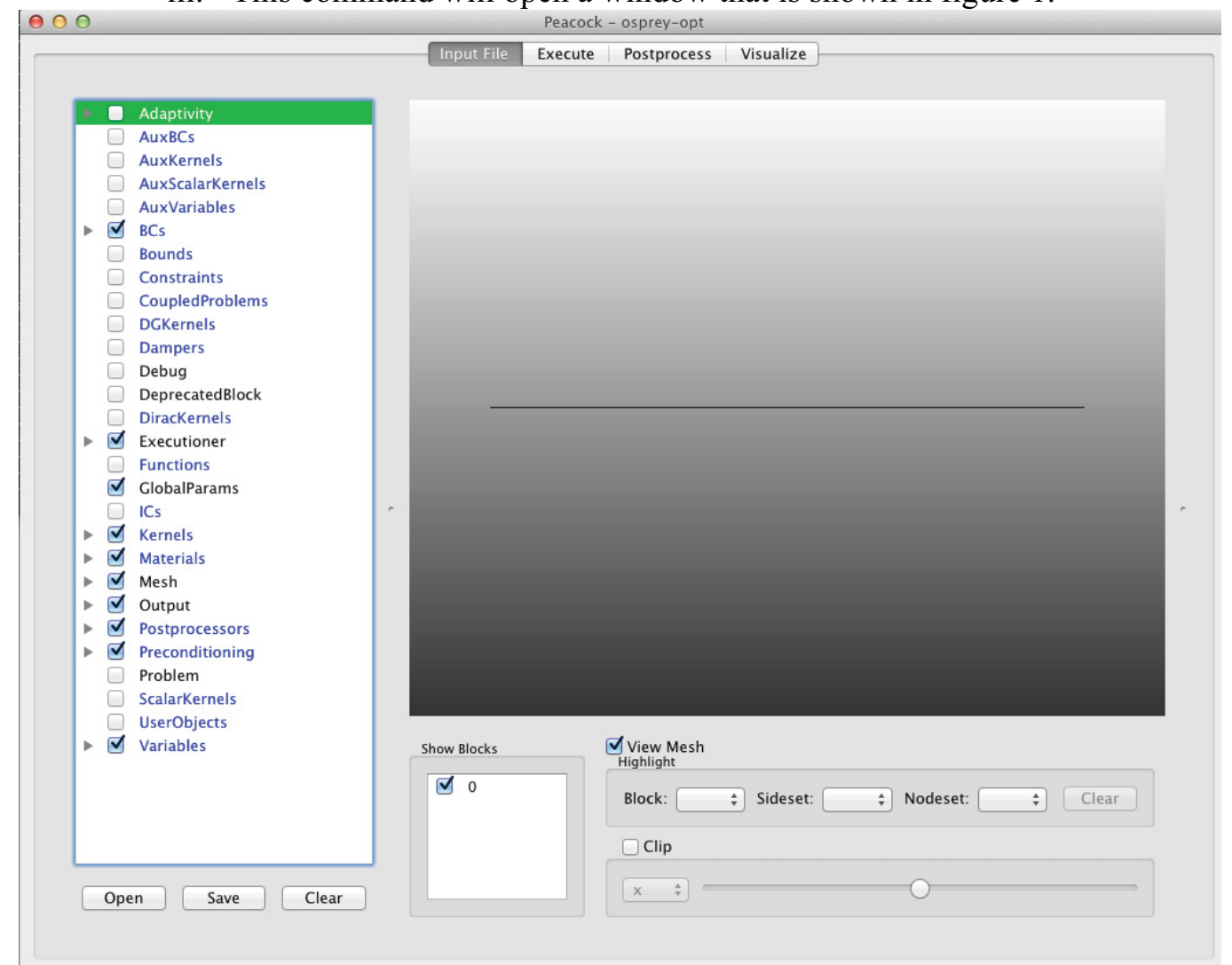

Figure 1: Peacock will look like this when it is opened.

9. Modify Parameters 
a. Double click on GlobalParams in list on left side of window

b. Go through list of parameters and change Value

i. Comment section shows units used and has brief description of parameter

c. Click on "Apply" button

10. Modify xmax in Mesh

a. If changed bed length in GlobalParams, must also change xmax

i. $\quad x \max =$ bed length

b. Double click on Mesh in list on the left

c. Scroll to xmax and input Value to be that of bed length

d. Can also modify the number of spatial stes (in the $\mathrm{x}$ direction) by changing $\mathrm{nx}$ value, however 50 seems to work well so do not change unless simulation fails to run.

e. Click "Apply"

11. Modify initial conditions

a. Click on arrow next to Variables in the list on the left side of the window

b. Double click on a variable to set the initial condition for that particular variable

c. Input initial_condition in Value column

d. Click "Apply"

e. Go through and set initial conditions for each variable

12. Modify simulation run time

a. Double click Executioner in the list on the left side of the window

b. Locate end time and change Value to be that of desired simulation time

c. Can change times step here also by changing value for $\mathrm{dt}$

d. Click "Apply"

13. Running the simulation

a. Click on Execute tab at the top of the window. The new window will look like shown in figure 2 .

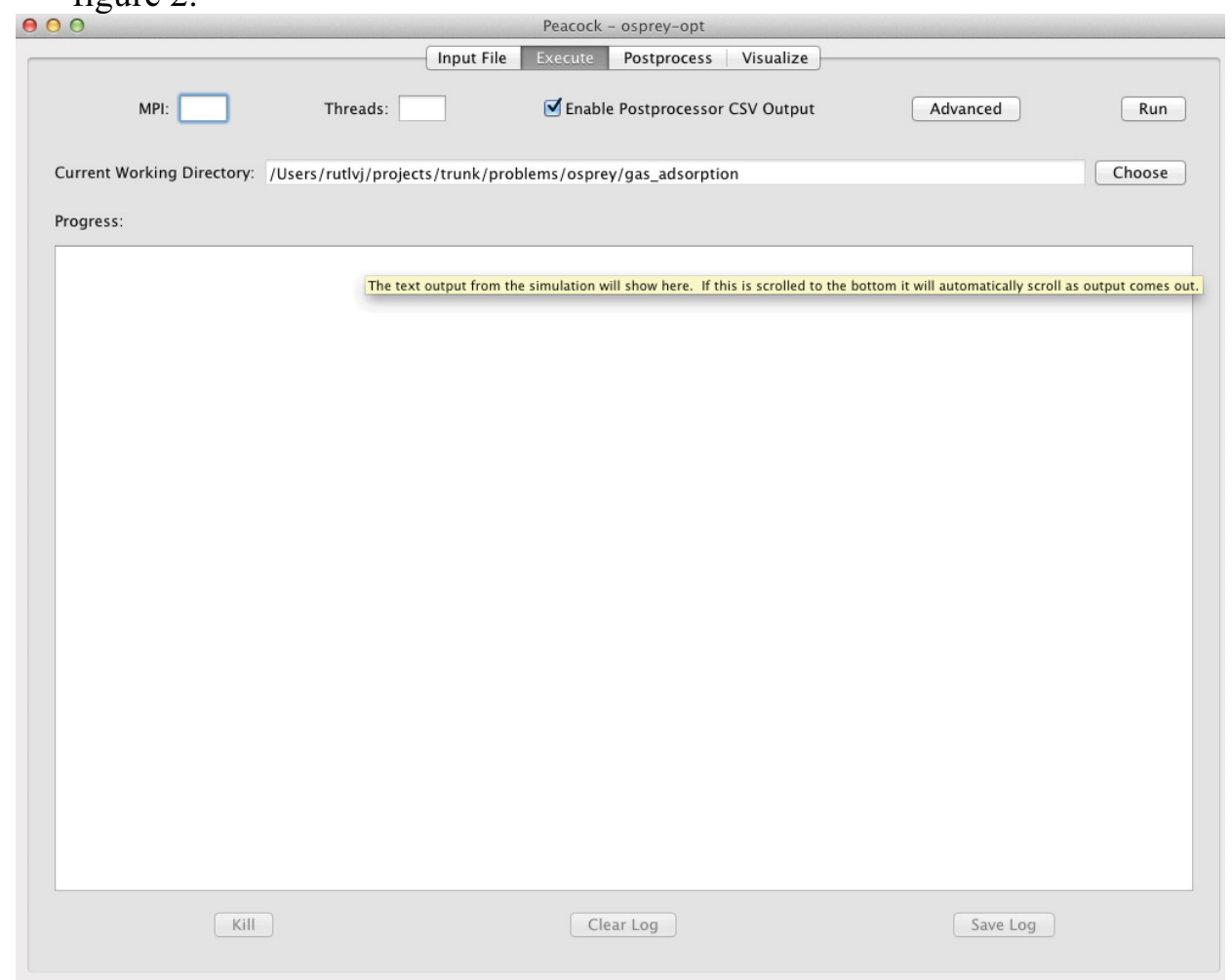

Figure 2: Execute tab of Peacock. 
b. Enter 1 in MPI box

c. Ensure "Enable Postprocessor CSV Output" is checked

d. Click "Run" button

i. Simulation as it's set up prior to any modifications to parameters, will run in a few seconds.

e. If you want to end simulation early, click "Kill".

14. Viewing graphical results as output by simulation

a. Click on Postprocess tab at top of window. It will look like shown in figure 3.

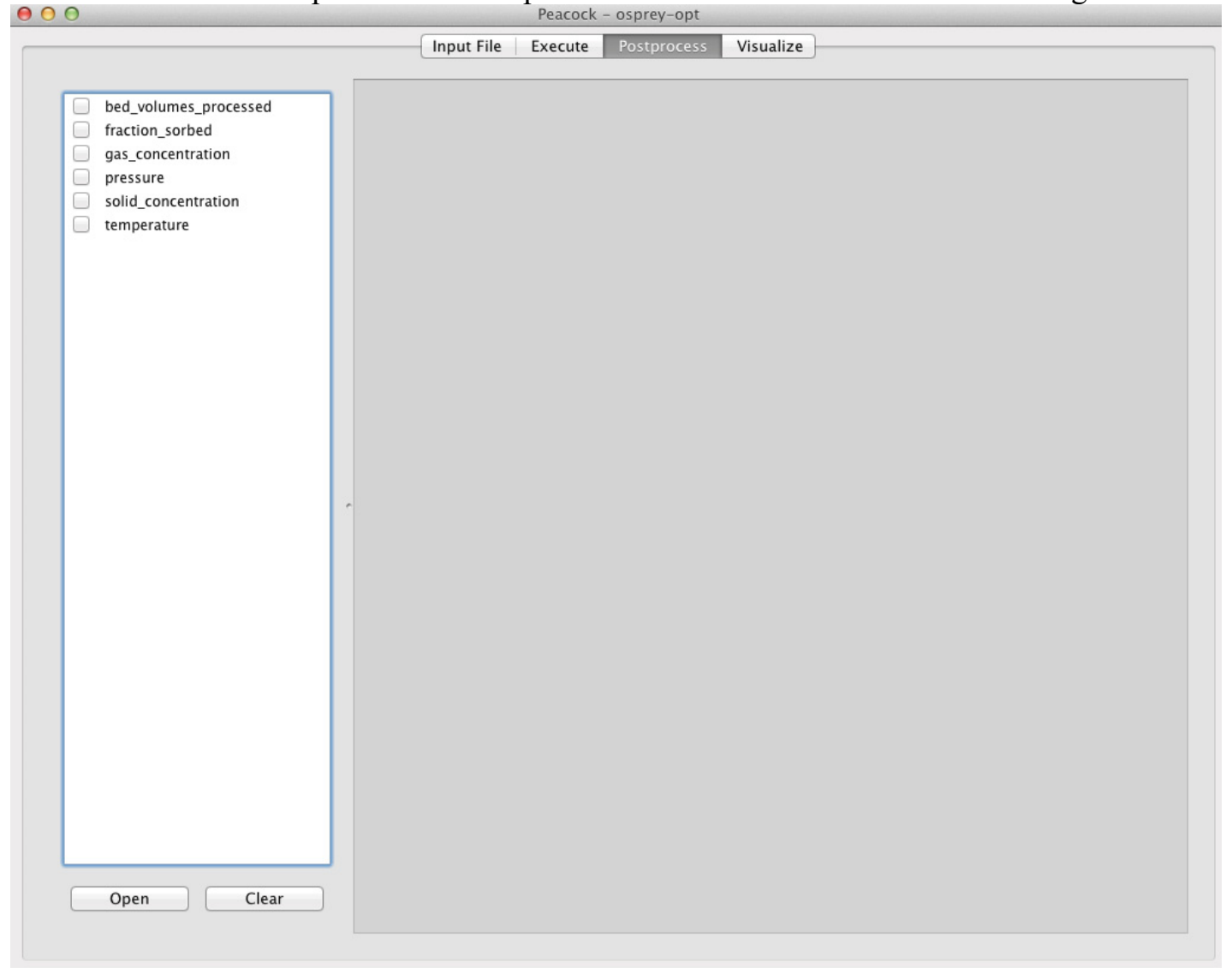

Figure 3: Postprocess window of Peacock.

b. To view plots of variables, check the box next to the variable listed on the left of the window and the plots will be generated in the grey area.

i. All plots are a function of time.

c. This can be done while simulation is running

15. Viewing the gradient along the bed length with time

a. Click on the visualize tab at the top of the window. It will look as shown in figure 4. 


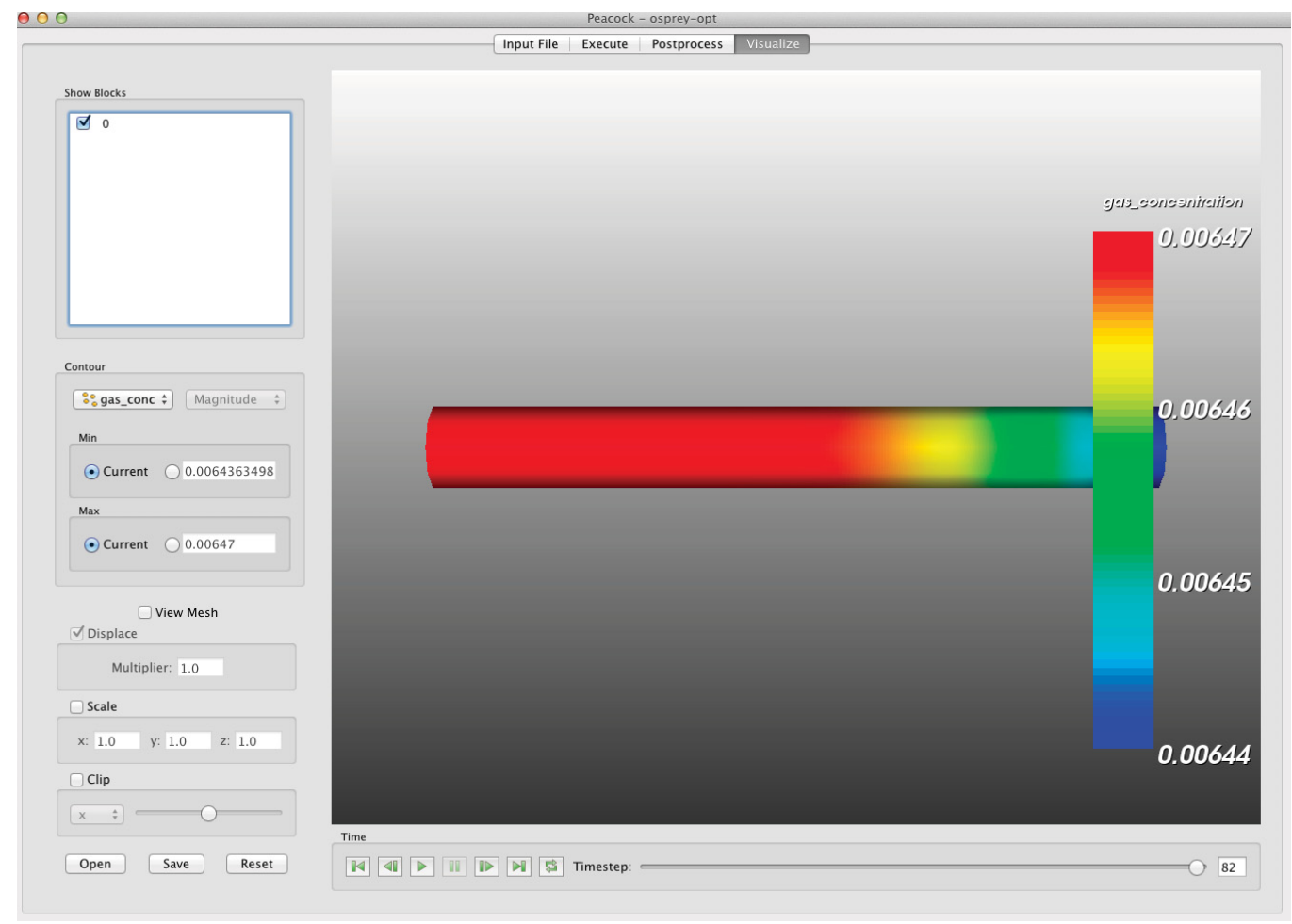

Figure 4: Visualize tab of peacock.

b. Choose the variable to visualize from the drop down list in the Contour box on the left side.

c. The min and max can be changed in the Contour box also.

d. Click on the play button at the bottom of the window to watch the gradient move along with bed length with each time step.

e. This can be done while simulation is running.

16. Viewing results in tabular form

a. Results shown in graphical form in the postprocess tab are saved as a .csv file that can be open in excel.

i. They will be saved in the same folder that the input file was located in.

17. A spreadsheet has been created into which the results, in tabular from the .csv file, can be pasted and will then graph the profiles.

a. This spreadsheet will be sent to you.

18. Any modifications you made to the input file by changing parameters and other values, can be saved as a new input file.

a. Go to the input file tab in Peacock.

b. Click the "save" button.

c. Choose name and directory to be saved under.

i. If want to be able to open in Peacock at a later time must save in the osprey folder in the problems directory.

d. Click save.

19. A different input file can be opened directly from Peacock.

a. Go to input file tab.

b. Click the "open" button.

c. Locate the input file to open and run in peacock. 


\section{REFERENCES}

1. Haefner, Daryl, et.al. "System Design Description and Requirements for Modeling the Off-Gas Systems for Fuel Recycling Facilities," INL-2010, Idaho National Laboratory, 2010.

2. Rutledge, Veronica J. "Adsorption Model for Off-Gas Separation," INL-2011, Idaho National Laboratory, 2011.

3. Gaston, Derek, et.al. "MOOSE Workshop” Training Manual. January 2012.

4. Ruthven, D.M. Principles of Adsorption Processes. pp. 225,317, John Wiley \& Sons, NY, 1984.

5. McCabe, Warren L., et.al. Unit Operations of Chemical Engineering. pp. 166, McGraw-Hill, New York, NY, 2005.

6. Ding, $\mathrm{Y}$, et.al. "Equilibria and kinetics of $\mathrm{CO}_{2}$ adsorption on hydrotalcite adsorbent," Chem. Eng. Sci., 2000, 55, 3461.

7. Simo, Marian. "Pressure Swing Adsorption Process for Ethanol Dehydration," pp. 57-58, Proquest LLC, Ann Arbor, MI, 2009.

8. Levan, M. Douglas, et.al. Perry's Chemical Engineers' Handbook - Section 16: Adsorption and Ion Exchange. pp. 16-23, McGraw-Hill, Lexington, KY, 2010.

9. Xiao-Zhong, Chu, et.al. "Dynamic experiments and model of hydrogen and deuterium separation with micropore molecular sieve Y at 77 K." Chem. Eng. J., 2009, 152, 428-433.

10. Malek, A., et.al. "Determination of Equilibrium Isotherms Using Dynamic Column Breakthrough and Constant Flow Equilibrium Desorption." J. Chem. Eng. Data, 1996, 41, 25-32. 